\title{
Evolución histórica de la visión del petróleo como instrumento de Independencia Económica
}

\author{
Pedro José Osorio Prado \\ pedrojosopra@gmail.com \\ Universidad Bolivariana de Venezuela \\ (Venezuela)
}

Recibido: 17 de enero de 2018

Aprobado: 1 de marzo de 2018

\section{RESUMEN}

La presente investigación desde una perspectiva histórico crítica, a través del método socio-jurídico, con un diseño documental, por medio de la revisión y análisis documental, se planteó como objetivo general establecer la relación entre el petróleo y la independencia económica, por medio de una revisión de orden histórica y legal, abordando las diferentes visiones de utilización del petróleo como instrumento de independencia nacional, alcanzándose como principal aporte la necesidad de impulsar nuevas políticas en materia petrolera, principalmente en materia de industrialización y de contrataciones públicas, que permitan relacionar al petróleo con el fortalecimiento del sector productivo nacional y se establezca una apropiada vinculación con la economía nacional.

Descriptores: petróleo; independencia económica; renta internacional: industrialización; contrataciones públicas. 


\section{Historical evolution of the vision of oil as an instrument of Economic Independence}

\section{SUMMARY}

The following investigation has been carried out from a critical historical perspective, through the socio-legal method, with a documentary design, using review and documentary analysis, as a general objective a relationship between oil and economic independence was stablished, through a review of historical and legal order, addressing the different views of oil use as instrument of national independence, reaching as the main contribution the need to promote new policies in petroleum field, mainly in the area of industrialization and of public hiring, that allow to relate to petroleum wealth with the strengthening of the national productive sector and to establish a proper connection with the national and domestic economy.

Descriptors: oil; economic independence; international income; industrialization; public contracting.

\section{Introducción}

En la presente investigación, donde se plateo como objetivo establecer la relación entre el petróleo y la independencia económica, por medio de una revisión histórica y legal, queda en evidencia que Venezuela, a pesar de más de 100 años de extracción de petróleo, siendo de los primeros productores del mundo y haber nacionalizado la industria petrolera, no ha sido suficiente para alcanzar el desarrollo de las fuerzas productivas nacionales y la independencia económica, lo que justifica la revisión histórica crítica de los diferentes momentos, sus relaciones sociales, los actores que participan y las diferentes visiones del petróleo como instrumento para el desarrollo nacional.

Entre las visiones surgidas en Venezuela para el utilización del petróleo como instrumento de desarrollo nacional, se destacan: la captación de renta en el mercado petrolero internacional, la industrialización y el aprovechamiento de las necesidades de la industria para fomentar el desarrollo de las fuerzas productivas, a través de las compras públicas, analizando los siguientes momentos y aspectos: 
1. Petróleo y Económica en Venezuela, una realidad histórica, donde se analizan los orígenes de la industria petrolera como actividad económica de importancia nacional en 1902, la evolución de su regulación legal y las relaciones sociales y económicas hasta 1943.

2. Reforma Petrolera de 1943, donde se estudia el impacto del cambio de régimen concesionario de la industria petrolera venezolana en 1943, las condiciones políticas, sociales y económicas de Venezuela y el mundo, así como lo avances de la industria en esa momento histórico, especialmente la industrialización a través de la construcción de refinerías.

3. Nacionalización de la Industria Petrolera, momento histórico donde se analiza la Ley que Reserva al Estado la Industria y el Comercio de los Hidrocarburos de 1975, así como su contexto histórico, sociales y político particular, donde se estudian las relaciones sociales y los actores en la industria petrolera, pero sobre todo la visión del petróleo para el desarrollo nacional, la cual, en su implementación, no resultó beneficiosa para el desarrollo nacional, tal como queda plasmado en los indicadores económicos, de producción y en las manifestaciones culturales.

4. Compra Públicas, herramienta para el desarrollo, donde se analiza la visión específica del aprovechamiento de las necesidades de la industria para fomentar el desarrollo de las fuerzas productivas, a través de las compras públicas, estudiando propuesta de organismos intergubernamental como el SELA (Sistema Económico Latinoamericano y del Caribe), y el marco legal de las contrataciones públicas, así como el diagnostico del sector productivo nacional, evidenciando la ausencia de política para desarrollar esta visión.

5. Reforma petrolera del 2001, etapa más reciente de la industria petrolera en Venezuela, la cual inicia con la promulgación, vía habilitante, de la Ley Orgánica de Hidrocarburos en 2001, donde se platean las visiones de utilización del petróleo para el desarrollo productivo nacional, la cual, si se quiere, está en pleno desarrollo, auxiliado en el marco legal de contrataciones públicas, hasta los nuevos textos legales de la Asamblea Nacional Constituyente. 
6. El petróleo, las compras públicas y el desarrollo nacional, donde se precisan aspectos relacionados en el marco legal de los hidrocarburos y el de las contrataciones públicas, donde la última entra en auxilio de la primera para desarrollar la visión de las compras públicas para el desarrollo productivo nacional.

Estos momentos y aspectos son analizados desde una perspectiva histórica crítica, con énfasis en la utilización de fuentes documentales que permitieron conocer el contexto económico, político y social, principalmente con el uso de diarios y manifestaciones culturales, fundamentado en el diseño documental, la revisión y análisis documental.

Como resultado de la investigación, concluyendo, se destaca como principal aporte la necesidad de impulsar nuevas políticas efectivas en materia petrolera, especialmente en materia de industrialización y de compras públicas, que permitan establecer una apropiada vinculación del petróleo con el fortalecimiento del sector productivo nacional, en armonía con la economía nacional, las cuales, aunque han sido establecidas en los diferentes momentos no han sido desarrolladas, sin embargo, por Venezuela tener las reservas de petróleo más grande del mundo se tiene la oportunidad de promulgar políticas que, visibilizando e implementando efectivamente, permitan alcanzar la independencia económica.

\section{Método}

En la presente investigación se empleó el método socio-jurídico, en los términos planteados por Márquez (1997), el cual expone, "la finalidad de este tipo de investigación es evaluar la finalidad y funcionamiento del derecho" (p. 54). Tomando en cuenta que este tipo de investigación tiene "como objeto de estudio las normas jurídicas y los hechos económico-sociales y políticos que concurren en su nacimiento, vigencia y eficacia" (p. 54), concordando con García (2015), "el derecho es un producto social, que no es indiferente a la relación que regula”(p. 452), características que se ajustan a lo realizado.

En lo que corresponde a la aplicación del investigación socio-jurídica, destaca Márquez (1997), "es indispensable que la interpretación se mantenga en cuanta ciertas características de la realidad económica y social de donde emergen la normativa" ( $p$. 
56), de allí que se ha hecho hincapié en utilizar fuentes que permitan evidenciar el contexto económico y social del momento, principalmente con el uso de diarios y manifestaciones culturales. Tomando en consideración que el "derecho, y por tanto, la normativa, emana del grupo social y, por consiguiente, expresa la forma en que deben establecerse las relaciones sociales según dicho grupo" (p. 56), para esta investigación se tomó en consideración las relaciones sociales inmersas en la actividad petrolera, desde su perspectiva histórica.

\section{Petróleo y Economía en Venezuela, una realidad histórica}

Desde hace más de 100 años la historia republicana de Venezuela ha estado marcada por el petróleo, ya en 1902, durante el bloqueo de las costas venezolanas, el bombardeo de los principales puertos y ocupación de sus aduanas por parte de Gran Bretaña, Alemania, Francia, Italia y Holanda, para asegurarse pagos de la deuda de la Republica suspendida por el General Cipriano Castro, "ya se destacaba una concesión petrolera o, para ser más preciso, de asfalto naturaf', tal como menciona Bernard Mommer (2012, p. 2), dejando en evidencia que comenzaban los hidrocarburos a formar parte de la vida nacional, sin embargo, en aquel momento, "no era el petróleo lo que seguía atrayendo la atención de la industria. El asfalto que continuaba usándose en el estado natural en que se encontraba en los 'menes' o afloramientos superficiales, no había perdido su importancia", comenta el Dr. González Berti (1970, p. 42).

Desde el punto de vista legal, fue el 23 de enero de 1904 cuando el Presidente Cipriano Castro, "añadió a la nueva ley minera (...), una resolución que regulaba específicamente la explotación de hidrocarburos (esto es, asfalto, petróleo, alquitrán, etc.)", tal como afirma Lieuwen (2016), el cual sentencia, "Se reafirmó el principio de que el presidente podía administrar y otorgar estas (...). Se añadió a los impuestos mineros ordinarios un derecho de exportación de cuatro bolívares por tonelada, y el canon mínimo pasó a ser de 25\%", denotando el interés económico del Estado en la actividad petrolera. Otro elemento de esta ley, es el hecho que se "incluyen a los hidrocarburos en el concepto de minas", según menciona Hildergard Rondón de Sansó (2012, p. 151) cuando hace referencia al artículo 1 de la mencionada ley, que 
textualmente reza, "también se considerarán minas, el asfalto, el betún, la brea, el petróleo y demás sustancias semejantes" (p. 152)

Sin embargo, legalmente, aun la materia petrolera se consideraba un apéndice de la minera, incluso cuando en 1905, el mismo Cipriano Castro promulga la Ley de Minas, tal como menciona Rondón de Sansó (2012), "que se constituye como base legal de las concesiones petroleras (...) estableciendo beneficios impositivos para el Estado Venezolano de dos bolívares por hectárea"(p. 152), sin embargo con la promulgación del Reglamento de la Ley de Minas del 23 de febrero de 1906, cuando se estableció, "las concesiones serán otorgadas mediante 'contratos especiales' celebrados directamente entre el ejecutivo y los concesionarios" (p. 152), se consolido el control del gobierno sobre la actividad petrolera.

No fue hasta 1920, cuando se dicta la primera ley venezolana de hidrocarburos, la Ley sobre Hidrocarburos y demás Minerales Combustibles, elaborada por Gumersindo Torres, lo cual "regula la exploración y explotación de los yacimientos de hidrocarburos" (p. 164), menciona Rondón de Sansó (2012), sin embargo, evidenciando la importancia de los hidrocarburos en ese momento histórico, principalmente luego de los postguerra, ante las luchas entre Estados Unidos y Gran Bretaña para asegurar suministros de hidrocarburos, como lo menciona Lieuwen (2016), en el caso de la Venezuela Petrolera de la época afirma, "La competencia en Venezuela era intensa. Aunque las compañías inglesas tenían las únicas concesiones al finalizar la guerra, pronto los agentes americanos se lanzaron en busca de concesiones" (p. 41), a lo cual sentencia en 1920 refiriéndose al Departamento de Estado norteamericano, "ordenó a su legación, en Caracas, que ayudase a la Sinclair Oil Company a obtener una concesión, el ministro Preston McGoodwin le complació concertando una entrevista personal del representante de la compañía con el propio general Gómez" (p. 41)

Con respecto a la importancia de la Ley sobre Hidrocarburos y demás Minerales Combustibles de 1920 y la participación de Gumersindo Torres, afirma Trompiz Valles (2016), "Gumersindo Torres, quien impuso a las compañías petroleras una respetable renta del suelo como canon de arrendamiento de los yacimientos nacionales, con la Ley Petrolera de 1920",(p. 136) dejando en evidencia que la relación del petróleo con la 
economía en Venezuela estaba dada por la captación de renta, sin ninguna otra participación del Estado.

Ahora, desde el punto de vista económico y petrolero, el periodo entre 1920 y hasta 1943, "es en verdad el más fecundo y donde la expansión de la industria petrolera alcanza su altura" (P. 46) afirma González Berti (1970), incluso resalta, "el acontecimiento más importante en la historia de nuestra industria petrolera, ninguno había tenido tan profundas repercusiones en la vida económica de Venezuela" (p. 46) al referirse al inicio de la producción del pozo Los Barroso № 2 en el Campo La Rosa de Cabimas, o en palabras de Baptista (2012), "el ingreso nacional de Venezuela, en 1920, había sido, aproximadamente, 525 millones de bolívares" (p. 133), lo que al colocarlo en perspectiva en el periodo de 1920-1929 y considerando solamente la extracción y comercialización de petróleo, "se significa entonces que durante la referida década, la inversión reproductiva en el negocio del petróleo llegó a ser algo más de dos veces el monto del total del ingreso producido por el país antes del inicio franco de la explotación del recurso" (p. 133), al respecto, dice Mommer (2008):

Ya en 1928, Venezuela era el mayor exportador de petróleo y el segundo en cuanto a producción, después de EUA. Debido a la crisis económica mundial, el café y el cacao, productos tradicionales de exportación, sufrieron una considerable merma tanto en sus precios como en sus volúmenes, de la cual no pudieron recuperarse. En cambio, la renta petrolera se estabiliza al alto nivel de aproximadamente 50 millones de bolívares, transformándose así el petróleo en el factor decisivo de toda la economía del país (p. 87-88)

Esto, deja plenamente demostrado una verdad histórica, el petróleo es el factor decisivo en la economía nacional de Venezuela, cosa que se mantiene hasta nuestros días, lo que justifica la necesidad de analizar el petróleo como instrumento de la independencia nacional, así como las vías para que esto sea posible.

Reforma Petrolera de 1943

Con ocasión a la promulgación de la Ley de Hidrocarburos en la Gaceta Oficial № 31 Extraordinario del 13 de marzo de 1943, el Ministro de Fomento de entonces, Eugenio Mendoza Hijo, en declaraciones reseñadas por el diario El Heraldo el 14 de marzo de 1943 dice: 
Así ha acontecido con la promesa de resolver nuestro máximo problema, el del petróleo, cuya solución, equilibrada y justa, la puede palpar ya el pueblo venezolano en instrumento de magníficas proyecciones que es el estatuto petrolero (...). Esa ley, que crea nuestra independencia económica, que echa las bases para que Venezuela ocupe el puesto que le corresponde en la industrialización y el comercio de su petróleo, que provoca un aumento notable en nuestras entradas fiscales, que le da al Estado el poder y la intervención suficientes para el manejo y control de una industria tan compleja como la petrolera, al mismo tiempo que da ésta la requerida libertad de acción y la debida flexibilidad para su desarrollo y prosperidad, esa ley, digo, que es sin duda y será por muchos años uno de los más importantes documentos de nuestra vida económica (Rivas 1989, p. 96)

Palabras de Mendoza donde, resalta al petróleo como elemento conflictivo de nuestro país, pero siendo nuestra principal riqueza también deber ser instrumento de nuestra independencia económica, principalmente en dos sentidos, primero en el comercial, es decir, a través de la captación de renta en el mercado internacional, como históricamente se ha orientado, y segundo, por medio de la industrialización del petróleo, tal como se comenzó cristalizar en los años siguientes, con la construcción de refinerías.

En lo que respecta a la industrialización del petróleo, el diario El Heraldo del 22 de enero de 1944, reseñado por Rivas (1989) tituló: "5 Compañías Petroleros han Firmado Contrato para Construir sus Refinerías en Venezuela" (p. 130), a lo que refiere en el texto "se pidió a las compañías petroleras que construyeran refinerías en Venezuela" ( $p$. 130), entre ellas "La Standard Oil de Nueva Jersey, la Royal Ducth Shell, la Texas, Socony, Vacum y la Sinclair han firmado contratos para la construcción de refinerías" (p. 130), comenzando así el proceso de industrialización del petróleo en Venezuela.

Desde el punto de vista legal esta Ley Hidrocarburos de 1943, estipula en su Sección V, Capítulo I, lo relativo a las Concesiones de Manufacturas o Refinación, regulariza el trámite para este tipo de concesiones, en un intento por estimular la utilización del petróleo como instrumento de riqueza e independencia económica, estableciendo en el artículo 15 ejusdem, las facultades del Ejecutivo Nacional para fomentar la instalación de industrias de manufactura o refinación y transporte, pudiendo otorgar exoneraciones y franquicias de impuestos y derechos para la importación de materiales, enseres, 
maquinarias, instalaciones, edificios, útiles, entre otros, destinados a la actividad manufacturera o de refinación y transporte, exoneraciones de derechos de importación del petróleo para la refinación nacional, y regímenes, reglamentaciones y facilidades aduaneras especiales.

En lo relacionado con la refinación, La Ley de Hidrocarburos de 1943 establece en el primer aparte del artículo 5:

Queda facultado el Ejecutivo Federal para estipular con el que solicite cualquiera de las concesiones a que se refiere esta Ley, ventajas especiales para la Nación. Estas ventajas podrán consistir, entre otras, en (...) la obligación por parte del solicitante de manufacturar o refinar, por si mismo o por terceros, en plantas situadas en el territorio nacional, todos los productos que explote o parte de ellos.

En lo que respecta al impacto de la visión de industrializar el petróleo como instrumento de la independencia nacional fue considerable, como comenta Salvador de la Plaza (2012) al referirse a la obligación de las trasnacionales petroleras a refinar en nuestro país, "para 1960 y como resultado de la mencionada disposición, existían ya 15 refinerías - varias de gran capacidad - en las cuales los trusts internacionales refinaron $51.339 .541 \mathrm{~m}^{3}$, el 31\% de la producción de ese año"(p. 88), sin embargo, este impacto económico no se evidencia directamente en el sector productivo nacional, "la deformación del desarrollo económico del país se aprecia (...) al observar que mientras mayor va siendo el volumen de la producción petrolera y de su exportación, mayor va siendo también el déficit (...) debido al aumento de las importaciones" (p. 65), sentencia el mismo Salvador de la Plaza (2012), quedando en evidencia que no es suficiente para la independencia económica la captación de la renta en el mercado internacional de los hidrocarburos, ni la industrialización nacional del petróleo (refinación), sino no se fomenta el sector productivo nacional.

Otro aspecto de vital importancia para el desarrollo productivo nacional y la utilización del petróleo como instrumento de riqueza e independencia económica, fue la eliminación de la libre importación de las que gozaban las trasnacionales petroleras, tal como menciona la publicación del 22 de enero de 1944 del diario El Heraldo reseñada por Rivas (1989), "La ley de 1943 abolió la libre importación de equipos concedida a las 
compañías petroleras por el régimen de Gómez" (p. 130), tal como lo establecía el artículo 56 de la Ley de 16 de junio de 1921, sobre Hidrocarburos y demás Minerales Combustibles, publicada en la Recopilación de Leyes y Decretos de Venezuela (1921) que establece:

Los Contratistas gozarán de las franquicias siguientes: (...) d) La libre importación de las maquinarias, edificios, tubos, depósitos, embarcaciones, tractores, automóviles de exploración, envases desarmados (...) los que sean menester para los servicios de hospitalización e higiene de la Empresa, y en general todos los enseres, útiles y demás elementos destinados a la exploración y explotación de productos en bruto y refinería y extracción de los productos derivados. (p. 178)

Denotando un cambio en la política del gobierno, sumando otro sentido a la visión del petróleo como riqueza nacional e instrumento para la independencia económica, como lo es aprovechar las inversiones en máquinas, equipos y demás bienes necesarios para las trasnacionales petroleras para, por un lado, captar impuestos a las importaciones, y por el otro sentar las bases para un desarrollo industrial al servicio de la industria petrolera en nuestro país, punto que más adelantes seguiremos desarrollando.

Desde una perspectiva constitucional, esta ley del 43 se promulgo durante la vigencia de la Constitución de los Estados Unidos de Venezuela, sancionada por el Congreso Nacional el 16 de julio de 1936 publicada en la "Gaceta Oficial núm. Extraordinario del 21 de julio de 1936" (p. 907), reseñada por Brewer-Carías (1997), la cual otorga al Poder Federal la competencia de legislar sobre las "riquezas naturales del país" (912) en su artículo 15 numeral 4, así como la legislación "relativo al régimen de Aduanas para los cobros de derechos importación" (p. 913), de allí que se promulgara la Ley de Hidrocarburos del 43 permitiendo esta reforma legal.

Esta constitución de 1936 fue parcialmente reformada el 5 de mayo de 1945, publicada en la "Gaceta Oficial № 131 Extraordinario" (p. 937), reseñada por Brewer-Carías (1997) pero sin cambios en lo que corresponde al fundamento de la materia de los hidrocarburos. Igualmente en la Constitución de 1947, sancionada por la Asamblea Nacional Constituyente el 5 de julio de 1947 y publicada en la Gaceta Oficial № 194 extraordinario de 30 de julio de 1947 (p. 991), no se introdujeron cambios sustanciales, 
solo se cambió al Poder Federal por el Poder Nacional en las competencias del régimen de aduanas y administración de minas e hidrocarburos, prohibiendo las concesiones por tiempo indefinidas, esto sin reformas considerables hasta la constitución de 1961, como desarrollaremos más adelante.

Otro elemento importante al respecto de esta Reforma Petrolera del 43, fue la entrada en vigencia de la primera Ley de Impuesto Sobre la Renta en 1942, como parte de la misma reforma, las que en palabras de Salvador de la Plaza (2012):

Han significado para el progreso del país, pues de unos ingresos por concepto de impuestos petroleros de 73 millones en 1940, con base en una producción de petróleo de 183 millones de barriles año, para 1955 las percepciones se multiplicaron por 26, mientras que la producción se multiplicó solo por 4 (p. 89)

Evidenciando el éxito de esta reforma, la cual transformó, no solo el régimen jurídico de las concesiones petroleras, sino que estableció la soberanía impositiva en materia de impuestos, y sentó las bases para la industrialización y el aprovechamiento de las inversiones necesarias en la industria petrolera para captar impuestos adicionales y el desarrollo productivo nacional, con el objetivo de la independencia económica.

\section{Nacionalización de la Industria Petrolera}

Ahora bien, antes de referirnos a la importante figura de la nacionalización, es necesario considerar, aunque no es objeto de estudio del presente documento, La Reversión como figura jurídica fue uno de los grandes avances de la ley del 43, estableciendo La Reversión como un derecho del Estado, transcurrido 40 años de la concesión, de acuerdo al artículo 26 ejusdem, en función de proteger este derecho se sancionó la Ley sobre Bienes Afectos a Reversión en las Concesiones de Hidrocarburos del 6 de agosto de 1971, publicada en Gaceta Oficial № 29.577, la cual tenía como finalidad, como menciona Sader (2013), proteger "la expectativa de derecho a favor de la nación" (p. 148), específicamente, las obras permanentes, incluyendo las instalaciones, accesorios y equipos objetos de las concesiones.

En lo que corresponde a la Nacionalización de la Industria Petrolera en Venezuela, tal como lo reseña Rivas (2013a), el proyecto de ley con esta pretensión fue presentado 
por la Fracción Parlamentaria del Partido Copei el 12 de marzo de 1974 ante el Congreso Nacional (p. 43), conociéndose como ley de nacionalización, a lo que continuo la designación de "Comisión para estudiar adelanto de la reversión petrolera (...), reforma petrolera y reforma de la administración pública" (p. 57) por parte del recién juramentado Presidente Pérez, tal como lo publicó el diario El Universal el 23 de marzo de 1974, lo que evidencia que este tema petrolero era de especial atención para el Gobierno Nacional y la opinión pública.

Esta ley de nacionalización de la industria petrolera fue polémica desde su discusión en el Congreso Nacional, incluso el mismo el Contralor General de la República de la época, Dr. José Muci Abraham, tal como lo reseña Rivas (2013a), publicó el diario El Nacional el 17 de abril de 1975, "se encuentra una observación en relación con el polémico artículo 5 del proyecto de nacionalización Petrolera. Al señalar que el proyecto presentado por el Ejecutivo «se ha apartado de la orientación definida por la Comisión Presidencial»”" (p. 244), a lo que contestaron, ante el Congreso Nacional, directores del Ministerio de Minas, tal como quedo reseñado en el diario El Nacional del 23 de abril de 1975, "hablaron largamente de lo que hay que hacer en materia de exploración, refinación y comercialización, y la conclusión de todo esto podría ser que el artículo 5 del proyecto de Ley de nacionalización, no sólo es necesario sino imprescindible" (p. 249), quedando así en evidencia que la industrialización era un elemento fundamental para que el petróleo se considerará instrumento para la independencia económica, al igual que la captación de renta en el mercado internacional.

Otra opinión al respecto del mencionado artículo 5 del proyecto de ley de nacionalización, fue la ofrecida por Pérez Alfonzo, publicada en el diario El Nacional del 08 de mayo de 1975, de acuerdo a reseña de Rivas (2013a):

Una nacionalización chucuta es una nacionalización imperfecta, y no la deseamos, pero es preferible una nacionalización chucuta a que la industria siga en manos de las transnacionales - dijo en otra parte de su intervención. Pero es preferible otra nacionalización chucuta - la primera fue la del hierro - a que siga retardándose. (...) Ni siquiera la brecha abierta por el artículo $5^{\circ}$ y sus posibilidades de empresas mixtas deben retardar el proceso. (...) si después de todo se deja paso para renovadas inversiones extranjeras, se las combate a medida que intenten invadirnos por allí, hasta desalentarlas definitivamente. 
Por fortuna, en escala mundial se van reconociendo con claridad los maliciosos efectos de la inversión extranjera en nuestros países subdesarrollados (p. 206)

El 29 de agosto de 1975, el Presidente Pérez, en el salón Elíptico del Capitolio, firma el ejecútese a la Ley Orgánica que Reserva al Estado la Industria y el Comercio de los Hidrocarburos (LOREICH), publicado en Gaceta Oficial № 1.769 Extraordinario, con el objeto de extinguir las concesiones de exploración, explotación de yacimientos, manufactura o refinación, transporte, almacenamiento, comercio interior y exterior de petróleo, asfalto y demás hidrocarburos, sus sustancias explotadas y refinadas, según el artículo 1 de esta ley.

En lo que respecta a la utilización del petróleo como instrumento de independencia económica, en los sentidos hasta ahora analizados, es decir, por medio de la captación de renta en el mercado internacional, la industrialización del petróleo y la utilización de las necesidades de inversión de la industria petrolera para sentar las bases para un desarrollo industrial nacional, resaltan en esta ley los siguientes artículos:

Artículo 2. El comercio exterior de los hidrocarburos estará bajo la gestión y el control exclusivos del Estado, quien lo ejercer directamente por el Ejecutivo Nacional o a través de los entes estatales creados o que se crearen para realizar los fines de la presente ley.

Artículo 3. La gestión del comercio exterior de los hidrocarburos se efectuará teniendo como objetivos esenciales los siguientes: Llevar al máximo el rendimiento económico de la exportación, en concordancia con los requerimientos del desarrollo nacional; la conquista y conservación de un mercado exterior estable, diversificado y suficiente; el apoyo al fomento de nuevas exportaciones de productos venezolanos; la garantía del abastecimiento, en términos convenientes, de insumos, equipos y demás elementos de producción, así como también los bienes esenciales de consumo que el país requiera.

Artículo 5. El Estado ejercerá las actividades señaladas en el artículo $1^{\circ}$ de la presente Ley directamente por el Ejecutivo Nacional o por medio de entes de su propiedad, pudiendo celebrar los convenios operativos necesarios para la mejor realización de sus funciones, sin que en ningún caso estas gestiones afecten la esencia misma de las actividades atribuidas.

En casos especiales y cuando así convenga al interés público, el Ejecutivo Nacional o los referidos entes podrán, en el ejercicio de cualquiera de las señaladas actividades, celebrar convenios de asociación con entes privados, 
con una participación tal que garantice el control por parte del Estado y con una duración determinada. Para la celebración de tales convenios se requerirá la previa autorización de las Cámaras en sesión conjunta, dentro de las condiciones que fijen, una vez que hayan sido debidamente informadas por el Ejecutivo Nacional de todas las circunstancias pertinentes.

Observándose que, en rasgos generales, esta ley desarrolla principalmente el proceso de indemnización a las concesionarias, sin embargo en los artículos mencionados resalta, primero, el comercio de hidrocarburos queda bajo en control del Estado, o el ente creado para tal fin (artículo 2), y este comercio tendrá como objetivo, el petróleo como instrumento de desarrollo nacional, "fomento de nuevas exportaciones de productos venezolanos; la garantía del abastecimiento, en términos convenientes, de insumos, equipos y demás elementos de producción, así como también los bienes esenciales de consumo que el país requiera" (artículo 3), lo que se traduce en, el petróleo como instrumento de independencia económica. Segundo, se configuró la brecha advertida por Pérez Alfonzo al capital trasnacional mencionado por Rivas (2013a), cuando en el artículo 5 ejusdem, abre la posibilidad de los "convenios operativos" y a las "convenios de asociación", con los cuales, como se comentará adelante, se atenta contra la visión de utilizar al petróleo como instrumento para la independencia nacional en todos los sentidos planteados.

En relación al artículo 5 de esta ley, Alí Primera (2007) le dedicó en su canción "Ahora que el petróleo es nuestro", la siguiente frase: "Nosotros lo trabajamos nosotros lo refinamos señores, a esa comedia la gracia yo no le veo que nosotros trabajemos $y$ ellos con el mercadeo" (p. 208), denunciando como, usando la brecha descrita por Pérez Alfonzo, se utilizó este artículo a favor de las trasnacionales petroleras, específicamente, en la comercialización en el mercado internacional, es decir, a través de la captación de renta.

Sin embargo, esta ley tiene la particularidad que, como se comentó, solo regula el proceso de indemnización a las concesionarias, por lo quedo en plena vigencia, salvo algunas excepciones, la Ley de Hidrocarburos de 1943, con la salvedad que ahora las concesionarias serían entes del Estado, como el caso de la Corporación Venezolana del Petróleo, la cual, de Instituto Autónomo se convierte en sociedad mercantil, por 
disposición del artículo 6, parágrafo tercero, de la LOREICH, y no es afectada por las disposiciones de esta ley in comento, según el artículo 25.

En el contexto constitucional, esta ley, $\mathrm{LOREICH}$, es promulgada en la vigencia de la Constitución publicada en la Gaceta Oficial № 662 Extraordinaria del 23 de enero de 1961, la cual incluye dentro del Capítulo V sobre los Derechos Económicos La Reversión para las concesiones petroleras, en su artículo 103, "Las tierras adquiridas con destino a la explotación o exploración de concesiones mineras, comprendidas las de hidrocarburos y demás minerales combustibles, pasarán de plena propiedad a la Nación, sin indemnización alguna, al extinguirse por cualquier causa la concesión respectiva", donde se evidencia la importancia económica de la explotación petrolera para la economía nacional.

La LOREICH, en su artículo 101, concatenado con el artículo 97, parágrafo primero, establece la expropiación como vía para que el Estado, se reserve industrias, explotaciones o servicios de interés público y de utilidad social, en especial, industrias básicas, incluida la industria petrolera.

Estas dos figuras constitucionales se establecieron, La Reversión y la nacionalización o reserva del Estado, ambos con efectos económicos inmediatos diferentes, la primera no implicaba ningún tipo de indemnización, mientras que la segunda estipula un pago por parte del Estado; el gobierno de Carlos Andrés Pérez se decidió por la segunda. Al considerar los efectos para la independencia económica, como objeto de estudio de la presente investigación, tienen el mismo efecto, la actividad petrolera pasa a manos del Estado, por consiguiente, se abre una nueva perspectiva como opción para el aprovechamiento de las inversiones de la industria petrolera para sentar las bases del desarrollo del sector productivo nacional, considerando que siendo estas inversiones, ahora inversiones del Estado, podría direccionarlas para el provecho nacional.

A los efectos de administrar la industria petrolera, el Ejecutivo Nacional crea una Sociedad Anónima, que en un primer momento se llamó Petroven, tal como reseña Rivas (2013a) fue publicado el 31 de agosto de 1975 en el diario en El Nacional, el cual expresa "el presidente Carlos Andrés Pérez (...) juramento a los miembros de la Directiva de la Sociedad Petróleos de Venezuela, Petroven, empresa matriz de esta 
industria nacionalizada" (p. 308), siendo su primer presidente el General Rafael Alfonzo Ravard.

Sin embargo, ya para 1978 en declaraciones de Pérez Alfonzo, reseñada por Rivas (2013b) de una publicación del diario El Nacional del 8 de octubre de 1978, esgrimía:

No puede aceptarse que PDVSA fije motus propio que «el signo de la industria en los años por venir seguirá siendo la expansión en todos los órdenes de sus actividades». Semejante disparate es la consecuencia de la obnubilación de camarillas de tecnócratas envanecidos por el poder abusivo que a veces logran atrapar. La expansión para PDVSA se convierte en contracción para los dueños del negocio. En dólares constantes, la participación fiscal pasó de \$ 7,21 en 1974 a $\$ 4,24$ en 1978. Mientras ellos aprovechan la expansión en todos los órdenes, la inversa, la contracción, continuará siendo el signo fatal para el indefenso pueblo venezolano.

Donde resalta, PDVSA comienza a desarrollar una política propia, pero lo más importante, a los efectos de la presente investigación, desde que PDVSA inicia actividades en lugar de consolidar al petróleo con instrumento de independencia económica, en lo que corresponde a la captación de renta a través de la producción de petróleo, comenzó un proceso en contrasentido a los intereses nacionales, en palabras de Mommer (2008) "después de la nacionalización (...), PDVSA se convirtió en algo así como un 'Estado dentro del Estado'. Sus ejecutivos venezolanos compartieron el punto de vista de las compañías petroleras internacionales, para quienes ellos habían trabajado durante muchos años" (p. 317).

El petróleo como instrumento de independencia económica, a través de la renta y los ingresos fiscales, se vio altamente afectado en este periodo, ya que PDVSA tenía el objetivo de desplazar al ministerio, no cumpliendo con la política de maximización de los ingresos fiscales.

En lo que corresponde a la industrialización como formas de utilizar al petróleo como instrumento de independencia económica, con el solo comparar el anuario "PETRÓLEO Y OTROS DATOS ESTADÍSTICOS" (PODE) de los años 1976 y 2003, se evidencia luego de unas adecuaciones de unidades que, los hidrocarburos producidos según el PODE (1976) la producción de las refinerías en Venezuela era de 1.175,01 MBB (miles de barriles diarios) para 1966, llegando a un pico en el periodo 1966 - 1976, en el año 
1973 con 1.306,41 MBD, una producción en el año de 1976 de 986,03 MBD, mientras que para el periodo comprendido entre 1999 y 2003, según el PODE (2003), la producción más alta fue de 1079,41 MBD, siendo la más baja la del año 2003, con una promedio de 857,3 MDB. Estas cifras demuestran que, la capacidad de refinación en Venezuela, o industrializar el petróleo, a lo mucho se mantuvo entre 1966 y 2003, lo que significa que la nacionalización de la industria en el año 76 no represento ningún incremento en nuestra capacidad de refinar nacionalmente, por lo que, la intención del legislador de industrializar el petróleo presente desde la Ley de Hidrocarburos de 1943, nunca se cristalizó, perdiendo una oportunidad de utilizar los hidrocarburos como instrumento de independencia económica, a través de la industrialización.

Lo descrito anteriormente, es muestra del rumbo de la industria petrolera posterior a la nacionalización, principalmente en el terreno de la política, en el marco del derecho que rige la actividad petrolera sigue intacta, salvo algunas pequeñas modificaciones, movimientos como la "Apertura Petrolera", la cual, según Mommer (2008) "encaminó a la política petrolera venezolana hacia la reprivatización de la industria", o la "Internacionalización", donde, según el mismo autor, se comenzaron a comprar activos fuera de Venezuela, como "La primera respuesta de PDVSA a la implementación de un control de cambio en 1983" citando a Boue, sin embargo, estas acciones estaban amparadas por la brecha del artículo 5 de la Ley de Nacionalización tan denunciada.

Lo mencionado hasta ahora sobre el periodo post nacionalización, es muestra de cómo la visión de utilizar al petróleo como instrumento de independencia económica se abandonó en casi todos los sentidos. En el sentido de la captación de renta cayó el ingreso fiscal, en la industrialización poco o nada se incrementó la producción en nuestras refinerías con respecto a la producción previa a la nacionalización, y en materia de utilizar las necesidades de inversión de la industria para potenciar el sector productivo nacional, prácticamente fue el sector menos atendido.

Considerando que durante este periodo analizado, 1976 - 2001, las actividades petroleras son desarrolladas por una empresa del Estado, como lo es PDVSA, la compras de bienes, contratación de obras y prestación de servicios necesarias para el funcionamiento pudieran orientarse al sector productivo nacional, convirtiendo las 
compras de esta empresa del Estado en un motor para el crecimiento económico, y consiguientemente para la independencia económica.

En este caso particular de las compras públicas, en este periodo, entró en vigencia la Ley de Licitaciones publicada en Gaceta Oficial № 34.528 del 10 de agosto de 1990, la cual entro a "regular los procedimientos de selección del contratista por parte de los sujetos a que se refiere el Artículo 2 para la ejecución de obras, la adquisición de bienes y la prestación de servicios" según el artículo 1 de esta ley, así como otras disposiciones de inferior rango legal, pero todas orientadas a la selección del contratista, ninguna disposición se orientó a direccionar este volumen de compras a un sector nacional.

\section{Compras Públicas, herramienta para el desarrollo}

Como parte de la línea investigativa desarrollada en el presente documento, es necesario hacer mención a las compras públicas, aunque no como un momento, si considerándolas como una herramienta importante para el desarrollo, como plantea la misma exposición de motivos del Decreto con Rango, Valor y Fuerza de Ley de Contrataciones Públicas publicado en la Gaceta Oficial № 6.154 Extraordinario del 19 de noviembre de 2014, "La Contratación Publica constituye un importante porcentaje del Producto interno Bruto Nacional, donde la participación del Estado y los particulares en sus relaciones de intercambio, impulsan el desarrollo económico de la Nación".

En relación a la importancia de las compras públicas, SELA (2014) señala "El Estado, a través de su poder de compra, posee una capacidad insustituible de influir en el diseño de políticas públicas de desarrollo, fomentando la producción y comercialización de bienes y servicios más adecuados en términos sociales, ambientales y económicos" ( $p$. 9), afirmación confirmada en la exposición de motivos antes mencionada. Dentro de este poder de compras del Estado, la industria petrolera tiene uno de los más altos peso específico, según datos del SELA (2014), citando a fuentes del Banco Mundial, estable que nuestro país, la participación de las compras públicas tienen una participación de 12\% para el año 2012 (p. 11), por debajo del promedio en Latinoamérica y el Caribe, cuyo aporte es del $15,52 \%$, y muy por debajo de regiones 
como la Unión Europea (21,66\%), Oriente Medio y Norte y África (16,59\%), e incluso en el mundo $(17,87 \%)$ (p. 9).

Cuando contrastamos los datos anteriores con la Caracterización de las Capacidades Industriales Nacionales para satisfacer la demanda de bienes, obras y servicios de la Industria Petrolera, Gasífera, Petroquímica y Minera, 2ำ Avance, realizado por la Dirección Ejecutiva del Conglomerado Nacional Industrial Petrolera de Petróleos de Venezuela, S,A. (2015), donde, de un universo de 150 empresas (p. 10), de las cuales el $88 \%$, 132, estaban activas, pero solo están operando al $26 \%$ de su capacidad instalada (p. 14), 65\% de ellas indicaron ser o haber sido proveedoras de Petróleos de Venezuela, S.A. (p. 19),

Otro elemento importante al respecto, es considerar que, Petróleos de Venezuela, S.A. (2016) en su Informe de Gestión Anual 2016, con un Gasto de operaciones, venta, administración y generales en el Sector Nacional de 6.797 millones de dólares (M\$) y en el Sector Internacional de $2.388 \mathrm{M} \$$, lo que habla de un potencial importante para utilizar el poder de compras de PDVSA, del cual tenemos como indicio las cifras anteriores, para utilizar al petróleo como instrumento de independencia económica, sin embargo, al contrastarlo con las cifras indicadas en párrafo anterior, observamos que, la incidencia de las compras públicas, específicamente del sector petróleo, pudiese aumentar significativamente si se orientan efectivamente las compras de la industria petrolera al sector productivo nacional.

Visto esto, toma más importancia la vía de usar las necesidades de bienes, obras y servicios de la industria petrolera, para que el petróleo se consolide como un instrumento de la independencia económica, entendiendo que esa visión de las compras públicas es de reciente data, sin embargo, ante las enormes reservas de crudo, la intensa actividad de industrialización instalada y un sector industrial nacional por ocupar y crecer, reafirma esta idea.

\section{Reforma Petrolera del 2001}

Continuando con la evolución histórica, en un ambiente político diferente, luego de la victoria de Hugo Chávez en el año de 1998, se da la Reforma petrolera del 2001, 
posterior a la entrada en vigencia de la Constitución de la República Bolivariana de Venezuela, se promulga, por vía habilitante, el Decreto con Rango, Valor y Fuerza de Ley Orgánica de Hidrocarburos publicada en Gaceta Oficial № 37.323 del 13 de noviembre de 2001 (LOH2001), transformando el régimen legal de los hidrocarburos, siendo la ley que efectivamente deroga la Ley de Hidrocarburos del 43, la LOREICH y la ley de nacionalización, entre otras leyes del derecho de los hidrocarburos.

Entre los aspectos principales de esta reforma están los mencionados por Araque (2002), "la necesidad inaplazable de restablecer el control del Poder Público Nacional sobre los recursos de hidrocarburos" (p. 191), "Restablecer el derecho del Estado a definir y garantizar una contribución patrimonial por el acceso al recurso natural' ( $p$. 192), "Restablecer el rol de Pdvsa y de las distintas operadoras ya existentes o futuras como instrumentos dedicados exclusivamente a las actividades de exploración, extracción, transporte, refinación y distribución de los hidrocarburos y sus productos elaborados" (p. 194), "Garantizar el mayor beneficio para la nación en las actividades de mayor rentabilidad" (p. 194), "Dar un nuevo impulso a los procesos de industrialización de los hidrocarburos para mejorar la composición de la cesta de exportación venezolana" (p. 194), "La separación contable de las actividades extractivas de las actividades de transformación y comercio"(p. 195), "El desarrollo de nuevos factores productivos nacionales" (p. 196), "La armonización de las leyes y la reforma institucional", "Fortalecer la participación de Venezuela en el mercado energético mundial" (p. 198), y "El mercado interno de productos" (p. 197).

A los efectos de la presente investigación, estos aspectos de la reforma petrolera del 2001 aportados por Araque (2002), se agruparan de acuerdo a las vías analizadas para utilizar el petróleo como instrumento para la independencia económica, a saber, captación de renta, industrialización del petróleo y las compras públicas de la industria petrolera.

Con punto previo, tal como se ha mencionado, esta reforma petrolera fue parte de una reforma mayor, la refundación del Estado, que comenzó la entrada en vigencia de la Constitución de la República Bolivariana de Venezuela, de allí que para comprenderla en toda su extensión, es necesario considerar esta relación. 
Entre los aspectos de la reforma petrolera del 2001 que se pueden relacionar con la captación de renta, encontramos: 1. Restablecer el derecho del Estado a definir y garantizar una contribución patrimonial por el acceso al recurso natural, 2. Garantizar el mayor beneficio para la nación en las actividades de mayor rentabilidad, 3. La separación contable de las actividades extractivas de las actividades de transformación y comercio.

Al respecto de la captación de renta y la reforma petrolera del 2001, se desarrolló el artículo 113 de la Constitución de la República Bolivariana de Venezuela, concatenado con el artículo 44 de la LOH2001, con "una regalía de 30\%, flexibilizándola hacia abajo hasta un 16 2/3 \% para el caso de los crudos extrapesados de la faja del Orinoco" (p. 193), según comenta Araque (2003), otro elemento al respecto, es el relacionado con las empresas mixtas, las cuales expresa el mismo autor, "De allí la disposición del artículo 22 de la $\mathrm{LOH}$ estableciendo una participación mayor de $50 \%$ del capital social en las empresas mixtas dedicadas a las actividades primarias", garantizando el control del Estado. En lo relacionado a las medidas de separación contable de las actividades, estas además de aportar a la transparencia "la empresa podrá desarrollar políticas y planes para incrementar su productividad y el Estado, a su vez, verá facilitado el control de las contribuciones que le corresponden" (p. 196).

En lo relacionado con la industrialización, 1. Dar un nuevo impulso a los procesos de industrialización de los hidrocarburos para mejorar la composición de la cesta de exportación venezolana, en este particular ya comentado para el periodo histórico anteriormente estudiado, refuerzo Araque (2002) "la Ley de 1943 ya tenía una orientación industrializadora", sin embargo, Araque citando a Boue expresa "en lugar de incrementar aún más la capacidad de procesamiento dentro del país, esto se hizo en el exterior a través de la llamada internacionalización petrolera", tal como se ha analizado, por lo cual esta reforma petrolera del 2001, cambio los artículos 10 y 52 de la LOH2001, donde, por un lado busca convertir al "petróleo en una industria industrializadota" y por el otra estimula los proyectos orientados a la industrialización de los hidrocarburos para estimular la formación de capitales nacional y el incremento del valor agregado nacional en conjunto con la competitividad. 
Para el caso de las compras públicas como mecanismo de desarrollo en la utilización del petróleo como instrumento de independencia económica, 1. El desarrollo de nuevos factores productivos nacionales, en este particular, la LOH2001, en desarrollo de múltiples principios constitucionales, en especial, el artículo 18, "para estimular la creación y consolidación de empresas operadoras, de servicios, de fabricación y suministro de bienes de origen nacionaf', además, en este sentido, se transformó el artículo 5, tan cuestionado, estableciendo que la actividades relacionadas con el petróleo:

Estarán dirigidas a fomentar el desarrollo integral, orgánico y sostenido del país, atendiendo al uso racional del recurso y a la preservación del ambiente. A tal fin se promoverá el fortalecimiento del sector productivo nacional y la transformación en el país de materias primas provenientes de los hidrocarburos, así como la incorporación de tecnologías avanzadas. Los ingresos que en razón de los hidrocarburos reciba la Nación propenderán a financiar la salud, a la educación, a la formación de fondos de estabilización macroeconómica y a la inversión productiva, de manera que se logre una apropiada vinculación del petróleo con la economía nacional, todo ello en función del bienestar del pueblo. (p. 196)

Ahora, con incidencia en, prácticamente, todas las vías planteadas en la presente investigación tenemos, 1. La necesidad inaplazable de restablecer el control del Poder Público Nacional sobre los recursos de hidrocarburos, 2. Restablecer el rol de PDVSA y de las distintas operadoras ya existentes o futuras como instrumentos dedicados exclusivamente a las actividades de exploración, extracción, transporte, refinación y distribución de los hidrocarburos y sus productos elaborados, 3. La armonización de las leyes y la reforma institucional, 4. Fortalecer la participación de Venezuela en el mercado energético mundial, y 5 . El mercado interno de productos, estos elementos bien pudieran tener relación con las anteriores, pero es necesario considerar, que si bien son fundamentales para la reforma petrolera del 2001, a los efectos de la presente investigación no tiene una incidencia directa.

El petróleo, las compras públicas y el desarrollo productivo nacional

Finalmente, al revisar éste último aspecto podemos precisar algunas conclusiones, no obstante, es importante resaltar la relación entre el Derecho de los Hidrocarburos, 
como regulación legal de la actividad petrolera, y como esta puede cumplir sus fines establecidos en la Ley Orgánica de Hidrocarburos, publicada en la Gaceta Oficial № 38.443 del 24 de mayo 2006, con reimpresión publicada en Gaceta Oficial № 38.493 del 4 de agosto de 2006, en su artículo 5 que establece "se promoverá el fortalecimiento del sector productivo nacional (...). Los ingresos que en razón de los hidrocarburos reciba la Nación propenderán (...) la inversión productiva, de manera que se logre una apropiada vinculación del petróleo con la economía nacional (...)", y es su artículo 18:

El Ejecutivo Nacional adoptará medidas que propicien la formación de capital nacional para estimular la creación y consolidación de empresas operadoras, de servicios, de fabricación y suministro de bienes de origen nacional para las actividades previstas en esta Ley. En tal sentido, el Estado, los entes y las empresas a que se refiere esta Ley, deberán incorporar en sus procesos de contratación, la participación de empresas de capital nacional en condiciones tales que se asegure el uso óptimo y efectivo de bienes, servicios, recursos humanos y capital de origen venezolano.

Por lo antes comentado, se hace imprescindible analizar el marco legal de las contrataciones públicas, considerando que, es la única forma de cumplir con lo establecido en los artículos anteriormente transcritos, referidos a fortalecer el sector productivo nacional, vincular apropiadamente el petróleo con la economía nacional e incorporar en los procesos de contratación a la empresas de capital nacional, asegurando un uso optimo y efectivo de bienes, servicios, recursos humanos y capital de origen venezolano, auxiliándose el Derecho de los Hidrocarburos con el Derecho Administrativo, en su especialidad, contrataciones públicas.

Desde la entrada en vigencia de la primera Ley de Licitaciones, publicada en Gaceta Oficial № 34.528 del 10 de agosto de 1990, hasta la reforma publicada en Gaceta Oficial № 5.556 Extraordinario del 13 de noviembre de 2001, por vía habilitante, el objeto de esta ley fue regular el proceso de selección de contratistas para la ejecución de obras, adquisición de bienes y prestación de servicios, en función de salvaguardar el patrimonio pública, la transparencia y evitar la corrupción, sin que las compras públicas se consideran mecanismos de desarrollo, como ya organismos internacional las consideraban, entre ellas, la Organización de Naciones Unidades, y su organismo adscrito, Comisión de la Naciones Unidas para el Derecho Mercantil Internacional 
(CNUDMI o UNCITRAL por sus siglas en ingles), quienes ya el 16 de junio de 1993 la CNUDMI (1993) aprobaron este modelo, que plantea entre sus considerando: “a) alcanzar una economía y eficiencia máxima en las contrataciones públicas, b) fomentar y alentar la participación de proveedores y contratistas en el proceso de contratación (...), c) promover la competencia entre proveedores (...)" (p. 305), tal como reafirmado por la misma CNUDMI (2014) en su versión 2014 de esta ley modelo.

Volviendo al caso de la regulación legal en Venezuela de las contrataciones públicas, la entrada en vigencia de la Ley de reforma Parcial del Decreto № 5.929 con Rango, Valor y Fuerza de Ley de Contrataciones Públicas, publicada en Gaceta Oficial № 39.165 del 24 de abril de 2009, cuando se incluye en el objeto de la ley, articulo 1, "finalidad de preservar el patrimonio público, fortalecer la soberanía, desarrollar la capacidad productiva (...), de manera de coadyuvar al crecimiento sostenido y diversificado de la economía", no está orientado perfectamente a la visión de utilizar las compras del Estado, especialmente el petróleo, como instrumento de independencia nacional y apoyo al sector productivo.

En las modificaciones realizadas a esta ley, Decreto con Rango, Valor y Fuerza de Ley de Contrataciones Públicas (LCP), publicada en Gaceta Oficial № 1.399 Extraordinario del 19 de noviembre de 2014, se mantuvo tal finalidad, incluso se profundizo, al establecer "Los procesos a que se refiere el presente Decreto con Rango, Valor y Fuerza de Ley, son de obligatorio cumplimiento, salvo las excepciones aquí previstas", como párrafo único en su artículo 1.

Además, esta LCP incluye un Capítulo III Medidas de Promoción de Desarrollo Económico, donde establece, como facultad del Presidente de la República dictar medidas temporales para favorecer a la "pequeña y mediana industria, cooperativa y cualquier otra forma de asociación comunitaria", en su artículo 11, dentro del cual se entienden incluidas, las nuevas formas de propiedad establecidas en la Ley Orgánica del Sistema Económico Comunal, así como Preferencia en Producción Nacional, como facultad de los contratantes cuando estos bienes y servicios provienes de financiamiento público, según el artículo 12, medida por demás coherente, y establece 
también ventajas a los bienes, obras o servicios con alto Valor Agregado Nacional, en el artículo 13.

Sin embargo, en adición a la anteriormente indicado, el 11 de enero de 2018 entra en vigencia la Ley Constitucional Contra la Guerra Económica para la Racionalidad y Uniformidad en la Adquisición de Bienes, Servicios y Obras Públicas, emanada de la Asamblea Nacional Constituyente publicada en Gaceta Oficial $N^{\circ} 41.318$; con el objetivo principal, luego de analizar su contenido, de "facilitar los mecanismos de control de tales procesos (la contratación pública), y estimular la participación equilibrada de todos los agentes económicos" (artículo 1), siendo las principales innovaciones la modificación de una nueva Unidad Tributaria para las contrataciones públicas, la UCAU, algunas medidas de simplificación de trámites administrativos, reforzar las medidas para incentivar la producción nacional, como las relativas al Valor Agregado Nacional y la promoción de nuevos actores, siendo su mayor implicación para el sector petrolero la facultad de los entes con fines empresariales, como PDVSA, filiales y empresas mixtas, de establecer regímenes especiales de contratación.

La facultad para establecer regímenes especiales de contratación se cristalizó para PDVSA, filiales y empresas mixtas con la entrada en vigencia del Decreto 3.368 del Ejecutivo Nacional, Decreto № 44 en el Marco del Estado de Excepción y Emergencia Económica, mediante el cual se establece un Régimen Especial y Transitorio para la Gestión Operativa y Administrativa de la Industria Petrolera publicada en Gaceta Oficial $\mathrm{N}^{\circ} 41.376$ de fecha 12 de abril de 2018, modificado parcialmente por Aviso Oficial del Vicepresidente Ejecutivo publicado en la Gaceta Oficial № 41.390, donde básicamente se establecieron dos medidas, la primera orientado modificar las modalidades de selección, a los efectos que la inmensa mayoría de las contrataciones de PDVSA, filiales y empresas mixtas se haga por Contratación Directa y Consulta de Precios, quedando vigente la LCP casi en su totalidad, y por el otro la instrucción al Ministerio del Poder Popular de Petróleo a establecer un régimen especial permanente para PDVSA, filiales y empresas mixtas al vencimiento de este régimen transitorio.

El régimen para PDVSA, filiales y empresas mixtas luego fue instrumentalizado mediante las Resoluciones 051 y 052 del Ministerio del Poder Popular para Petróleo, 
publicadas en Gaceta Oficial 41.394 de fecha 10 de mayo de 2018, donde solo establecieron procesos internos de PDVSA para la contratación de bienes, obras y servicios.

Sin embargo, esta especialidad normativa para PDVSA, filiales y empresas mixtas poco o nada aportó en la visión de utilizar al petróleo para fortalecer el sector productivo nacional, vincular apropiadamente el petróleo con la economía nacional e incorporar en los procesos de contratación a la empresas de capital nacional, por lo menos no directamente, quedando un gran vacío en los relacionado con una verdadera política de contratación pública, la cual, es estos aspectos legales tienen un mayor piso jurídico.

\section{Resultados y Discusión}

El petróleo venezolano ha sido un factor económico fundamental en la vida nacional en los últimos 100 años, sin embargo, la visión que de este se ha tenido, respecto a su incidencia en la independencia económica y el sistema económico nacional, ha evolucionado en el tiempo, como ejemplo de esta evolución se pueden diferenciar, desde una perspectiva legal, la vigencia de la Ley sobre Hidrocarburos y demás Minerales Combustibles en 1920, la Ley de Hidrocarburos de 1943, la LOREICH de 1975 y la Ley Orgánica de Hidrocarburos de 2001, siendo analizados durante este investigación, tres periodos, la Reforma Petrolera del 43, la Nacionalización de la Industria Petrolera y la Reforma Petrolera del 2001, y dos aspectos, Compras Públicas, herramienta para el desarrollo, y El petróleo, las compras públicas y el desarrolla nacional, estudiado en estos la visión de utilizar el petróleo como instrumento para la independencia, en tres sentidos, por medio de la captación de renta, la industrialización del petróleo y el aprovechamiento de las necesidades de inversión de la industria petrolera para apoyar el sector productivo nacional a través de las compras públicas.

El primer momento se estuvo marcado por la captación de renta, por medio de las regalías u otras formas de impuestos, así como dispuestas entre país extranjeros, como Gran Bretaña y Estados Unidos principalmente, las trasnacionales petroleras, así como diversas clases políticas y económicas venezolanas, las cuales se regularon jurídicamente en diversas textos legales, como la Ley de Minas de 1904 y 1905 y su 
reglamento de 1906, así como la Ley sobre Hidrocarburos y demás Minerales Combustibles de 1920, primero ley petrolera venezolana, primer momento sin dudas exitoso, considerando el aumento considerable de los ingresos petrolera por el concepto de renta petrolera, durante el cual Venezuela llegó a ser el principal productor de petróleo del mundo.

Durante la Reforma Petrolera del 43, se impulsó la captación de renta por medio del fortalecimiento de la política fiscal, en la regulación y homogenización de las regalías e impuestos aplicables a la explotación y comercialización del petróleo, además, durante este periodo se inició el proceso de industrialización del petróleo, consecuentemente, la construcción de refinerías en Venezuela, abriendo otra perspectiva en la forma de utilizar al petróleo como instrumento de la independencia económica. Por último, se tomaron, tímidamente, medidas para utilizar las necesidades de bienes, obras y servicios de la industria petrolera en el fortalecimiento del sector productivo nacional, principalmente con la eliminación de la libre importación de las concesionarias para lo relacionada con la exploración y explotación del petróleo, consolidándose, aun en medidas diferentes, las tres visiones de utilización del petróleo para el desarrollo nacional, resaltando la captación de renta, con la uniformidad de las concesiones y el aumento de los impuestos, así como la industrialización, por la construcción de refinerías en Venezuela.

En lo que corresponde a la Nacionalización de la Industria Petrolera, con la interpretación del artículo 5 de la LOREICH, se puede considerar un retroceso en la visión de utilizar el Petróleo como instrumento de independencia económica, reflejándose en la disminución de ingreso petrolero, el estancamiento de la producción en nuestras refinerías y la poca o escasa orientación de las compras de la industria petrolera al sector productivo nacional, todo esto de acuerdo a las cifras económicas analizadas analizadas.

Sin embargo, con la entrada en vigencia de la Ley Orgánica de Hidrocarburos del 2001, en el momento Reforma Petrolera del 2001, se consolidaron, desde el punto de vista legal, las tres visiones desarrolladas en la investigación, estableciendo utilizar el petróleo como instrumento de desarrollo, aumentándose el control del Estado sobre la 
industria, permitiendo incrementar la captación de renta por la comercialización en el mercado internacional del petróleo venezolano, sin embargo, en materia de refinación y la utilización de la compras públicas no se ha podido consolidar posterior a esta reforma.

Es necesario hacer especial énfasis en lo relacionado con la utilización de las compras públicas, principalmente las realizadas por industria petrolera, ya que, en este particular, para lograr una efectiva utilización del petróleo como instrumento de independencia económica, el Derecho de los Hidrocarburos debe auxiliarse en el Derecho Administrativo, principalmente, lo relacionado con las Contrataciones Públicas y el Decreto con Rango, Valor y Fuerza de Ley de Contrataciones Públicas vigente, el cual, incluye como objetivo "desarrollar la capacidad productiva y asegurar la transparencia de las actuaciones de los contratantes sujetos al presente Decreto con Rango, Valor y Fuerza de Ley, coadyuvando al crecimiento sostenido y diversificado de la economía", incluso faculta al Presidente de la República a dictar medidas temporales, incluyendo a los contratantes cuando se trate de bienes, obras y servicios financiado con patrimonio público.

Para esta forma de utilización de las compras públicas, se cuenta con un piso jurídico sólido con la entrada en vigencia de una serie de medidas orientadas a transformar los mecanismo de contratación en la Industria Petrolera, como la entrada en vigencia de la Ley Constituyente Contra la Guerra Económica para la Racionalidad y Uniformidad en al Adquisición de Bienes, Obras y Servicios de enero 2018, junto a todos los actos normativos mencionados, sin embargo, aún falta la orientación hacia el donde se debe dirigir esta capacidad de compra, lo que solo es posible con un Política para PDVSA, filiales y empresas mixtas, lo que hasta ahora no ha permitido cristalizar esa visión económica, a pesar de estar recomendada por organismos internacionales, las cuales reconocen a la compras públicas como instrumentos de desarrollo.

Habiendo analizado la perspectiva histórica y legal de la utilización del petróleo como instrumento para la independencia económica, desde una perspectiva histórica critica, en un contexto histórico, social y cultural, es necesario orientar la discusión hacia la voluntad política de los gobiernos en desarrollar las diferentes visiones del petróleo 
como instrumento político y económico, ya que hoy, a más de 100 años de explotación petrolera en nuestro país, no hemos podido cristalizar ese sueño, esta verdad histórica queda comprobada en los resultados de la Nacionalización de la Industria Petrolera, donde poco o nada se avanzó en los diversos sentidos analizados, por lo que es necesario concluir:

1. Independientemente de la visión sobre la utilización del petróleo como instrumento de la independencia, es necesario y urgente se priorice o instrumente a través de políticas nacionales, directrices, instrucciones o demás disposiciones imperativas para los órganos y entes del Estado, con voluntad política clara y una visión nacionalista, que permita direccionar efectivamente la política petrolera, en el marco del Derecho de los Hidrocarburos y auxiliándose en las demás ramas del derecho.

2. Es necesario profundizar la industrialización del petróleo, específicamente con la refinación y el aprovechando los diversos derivados para que sean procesados en Venezuela, a través de la industria de la petroquímica o similares, logrando obtener mayor valor de los productos y maximizando la participación en mercados internacional de productor intermedios o terminados de alto valor.

3. Habiéndose analizadas todas las visiones analizadas, la que menos ha sido desarrollada es la utilización de las compras públicas como instrumento de desarrollo nacional, aun existiendo un sector industrial nacional poco ocupado, lo que evidencia un direccionamiento de las compras del estado a la importación de bienes, con consecuencias graves para la industria nacional, y siendo de todas las visiones la de mayor probabilidades de implementación, ya que no requiere de grandes inversiones de capital, solo una política sólida, coherente y efectiva, y de una voluntad política.

Venezuela, con las reservas de petróleo más grandes del mundo, y considerando que el hidrocarburo no es solo combustible, sino la materia prima más versátil jamás usada por la humanidad, estamos en la obligación, como sociedad, de aprovechar muestras riquezas naturales no renovables en todas las formas posibles, lo que además de urgente para los venezolanos, sería una referencia mundial en la utilización política y económica del petróleo para desarrollo nacional, alternativa a la política petrolera impuesta desde las empresas trasnacionales. 


\section{Referencias Consultadas}

1. Araque, A. (2002). La Reforma Petrolera Venezolana de 2001. Revista Venezolana de Economía y Ciencias Sociales, volumen 8 (2), pp 189-200. Recuperado de http://biblioteca.clacso.edu.ar/ar/libros/venezuela/rvecs/araque.pdf.

2. Baptista, A. (2012). Teoría del Capitalismo Rentístico. Caracas, Venezuela: Ediciones Banco Central de Venezuela. ISBN: 978-980-394-067-6.

3. Brewer-Carías, A. (1997). Las Constituciones de Venezuela. Caracas, Venezuela: Academia de Ciencias Políticas y Sociales. ISBN: 980-6396-02-2.

4. Comisión de la Naciones Unidas para el Derecho Mercantil Internacional (1993). Ley modelo de la CNUDMI sobre la Contratación Pública. Nueva York, Estados Unidos: Naciones Unidas. Recuperado el día 10 de octubre de 2017 de: http://www.uncitral.org/pdf/spanish/texts/procurem/proc93/proc93-s.pdf.

5. Comisión de la Naciones Unidas para el Derecho Mercantil Internacional (2014). Ley modelo de la CNUDMI sobre la Contratación Pública. Nueva York, Estados Unidos: Naciones Unidas A/66/17. Recuperado de http://www.uncitral.org/pdf/spanish/texts/procurem/ml-procurement/2011-ModelLaw-on-Public-Procurement-s.pdf.

6. Decreto $N^{\circ} 1.399$ mediante el cual se dicta el Decreto con Rango, Valor y Fuerza de Ley de Contrataciones Públicas. Presidencia de la República. Gaceta Oficial N 6.154 Extraordinaria, 19 de noviembre 2014.

7. Decreto $N^{\circ} 1.510$ con Fuerza de Ley Orgánica de Hidrocarburos. Presidencia de la República. Gaceta Oficial 37.323, 13 noviembre 2001.

8. Decreto $N^{\circ} 1.557$ con Fuerza de Ley de Reforma Parcial de la Ley de Licitaciones. Presidencia de la República. Gaceta Oficial N 5.556, 13 de noviembre 2001.

9. Decreto $N^{\circ} 3.368$ mediante el cual se establece un régimen especial y transitorio para la gestión operativa y administrativa de la Industria Petrolera Nacional. Presidencia de la República. Gaceta Oficial 41.376, 12 de abril 2018.

10. De la Plaza, S. (2012). Historia y retos del petróleo en Venezuela. Volumen I. Caracas, Venezuela: Fondo Editorial Darío Ramírez. ISBN: 978-980-7189-09-5. 
11. García Fernández, D. y Witker Velásquez, J. (2015). La Metodología de la Investigación Jurídica en el Siglo XXI. Universidad Nacional Autónoma de México. 449-465. Recuperado de https://archivos.juridicas.unam.mx/www/bjv/libros/8/3983/24.pdf.

12. González Berti, Luis (1970). Compendio de Derecho Minero Venezolano volumen II. Mérida, Venezuela: Universidad de los Andes.

13. Ley constitucional contra la guerra económica para la racionalidad y uniformidad en la adquisición de bienes, servicios y obras públicas. Asamblea Nacional Constituyente. Gaceta Oficial 41.318, 11 de enero 2018.

14. Ley de hidrocarburos. Asamblea Nacional. Gaceta Oficial N 31 Extraordinario, 13 de marzo 1943. Recuperado de https://pandectasdigital.blogspot.com/2017/09/gaceta-oficial-de-los-estadosunidos-de 4.html.

15. Ley de Licitaciones. Congreso de la República de Venezuela. Gaceta Oficial № 34.528, 10 de agosto 1990.

16. Ley Orgánica que Reserva al Estado la Industria y el Comercio de los Hidrocarburos. Congreso de la República de Venezuela. Gaceta Oficial № 1.769 Extraordinaria, 29 de agosto 1975. Recuparado de http://www.pdvsa.com/images/pdf/marcolegal/ley organica que reserva al esta do la industria y el comercio de los hidrocarburos.pdf.

17. Ley de Reforma Parcial del Decreto № 1.510 con Fuerza de Ley de Orgánica de Hidrocarburos. Asamblea Nacional. Gaceta Oficial №38.443, 24 de mayo 2006.

18. Ley de Reforma parcial del Decreto $N^{\circ} 5.929$ con Rango, Valor y Fuerza de Ley de Contrataciones Públicas. Asamblea Nacional. Gaceta Oficial №39.165, 24 de abril 2018.

19. Lieuwen, E. (2016). Petróleo en Venezuela, una historia. Caracas, Venezuela: Fundación Editorial El Perro y la Rana.

20. Márques Sánchez (1997). Manual de Investigación Jurídica. Caracas, Venezuela: Editorial Buchivacoa.

21. Mommer, B. (2008). La Cuestión Petrolera. Caracas, Venezuela: Ediplus. ISBN: 978-980-259-940-0. 
22. Mommer, B. (2012). El régimen petrolero venezolano en los tribunales internacionales de arbitraje (primera parte). Le Monde Diplomatique, Edición Venezolana. Año IV, Número 35 (julio). Recuperado de https://issuu.com/suplementoslediplovlza/docs/el regimen petrolero vlzno i.

23. Ministerio de Energía y Minas (1976). Petróleo y Otros Datos Estadísticos. Caracas, Venezuela. Recuperado de http://www.mpetromin.gob.ve/portalmenpet/secciones.php?option=view\&idS=21.

24. Ministerio de Energía y Minas (2003). Petróleo y Otros Datos Estadísticos. Caracas, Venezuela: Autor. Recuperado de http://www.mpetromin.gob.ve/portalmenpet/secciones.php?option=view\&idS=21.

25.Petróleos de Venezuela, S.A. (2016). Caracterización de las Capacidades Industriales Nacionales para satisfacer la demanda de bienes, obras y servicios de la Industria Petrolera, Gasífera, Petroquímica y Minera, 2 do Avance. Recuperado de http://www.cnip.pdvsa.com/images/pdfcnip/2do Informe Caracterizacion.pdf.

26. Petróleos de Venezuela, S.A. (2016). Informe de Gestión Anual 2016. Recuperado de http://www.pdvsa.com/images/pdf/iga/IGA 2016 Compilado.pdf.

27.Primera, A. (2007). No cantar es perdernos. Caracas, Venezuela: Fundación Editorial El Perro y la Rana. ISBN 978-980-7163-56-9. Recuperado de http://www.elperroylarana.gob.ve/wp-content/plugins/pdfjs-viewershortcode/pdfjs/web/viewer.php?file=http\%3A\%2F\%2Fwww.elperroylarana.gob.v e\%2Fwpcontent\%2Fuploads\%2F2017\%2F02\%2Fno cantar es perdernos.pdf\&download =true\&print=true\&openfile=false.

28. Reimpresión Ley de Reforma Parcial del Decreto $N^{\circ} 1.510$ con Fuerza de Ley de Orgánica de Hidrocarburos. Asamblea Nacional. Gaceta Oficial № 38.493, 4 de agosto 2006.

29. Rivas, J. (2009). Historia Gráfica de Venezuela, Tomo II El Gobierno de Medina Angarita [CD Rom]. Caracas, Venezuela: Centro Editor C.A. ISBN: 978-9806995-03.

30. Rivas, J. (2013a). Historia Gráfica de Venezuela, Tomo XIV El Gobierno de Carlos Andrés Pérez - Primera parte- [CD Rom]. Caracas, Venezuela: Centro Editor C.A. ISBN: 978-980-6995-16-1. 
31. Rivas, J. (2013b). Historia Gráfica de Venezuela, Tomo XIV El Gobierno de Carlos Andrés Pérez - Segunda parte- [CD Rom]. Caracas, Venezuela: Centro Editor C.A. ISBN: 978-980-6995-16-1.

32. Rondon de Sansó, H. (2012). El Régimen Jurídico de los Hidrocarburos. Tercera Edición. Caracas, Venezuela: Editorial Arte. ISBN 978-980-12-5526-0.

33.Sader, R. (2013). Hacia la Nacionalización Petrolera. Caracas, Venezuela: Banco Central de Venezuela. ISBN: 978-980-39-4078-2.

34. Sistema Económico Latinoamericano y del Caribe (2014). Las compras públicas como herramienta de desarrollo en América Latina y el Caribe. SP/Di № 11-14, Septiembre 2014. Caracas, Venezuela. Recuperado de http://www.sela.org/media/268508/las-compras-publicas-como-herramienta-dedesarrollo-en-alc.pdf.

35. Trompiz Valles, H. (2016). La renta petrolera y los latifundistas durante el gomecismo. Caracas, Venezuela: Fundación Editorial El Perro y la Rana. ISBN 978-980-14-3379-8

(C) 2018 por el autor. Este artículo es de acceso abierto y distribuido según los términos y condiciones de la licencia Creative Commons Attribution (http://creativecommons.org/licenses/by/4.0/). 